\title{
Hardening Process Evaluation on Penetration of Foamed Epoxy Asphalt
}

\author{
Ming Huang \\ Post doctoral workstation \\ Shanghai Municipal Engineering Design Institute (Group) Co., Ltd., SMEDI \\ Shanghai, China \\ 07huangming@tongji.edu.cn
}

\begin{abstract}
Foamed epoxy asphalt, a kind of epoxy asphalt with a brand-new curing system, has excellent construction performance. This paper provided several new anhydride solidified agents used in Component $B$ of epoxy asphalt based on the diversifications on viscosity-temperature curves, and monitored the whole process of solidification, from slowing down the solidification, satisfying construction performance, providing long enough time of mixing, paving and compacting aspects, advanced appropriate solidifier system.
\end{abstract}

Keywords- Epoxy Asphalt; Solidifier; Penetration

\section{INTRODUCTION}

There are still many unresolved problems when epoxy resin used in asphalt, the effects of mixture test have a large number of factors, the amount of experiment is large, and the cost is high. Therefore, in this paper, researchers consider the combination of materials only to pre-exclude the unknown effects of stone. Researchers study of the chemical reaction mechanism of hardening process and changes of intensity to achieve more precise control, provide a new theoretical approach for the research and development of the epoxy-modified asphalt.

To make sure the content of hardener and the whole process of hardening, researchers can calculate in chemical ways, but only based on chemical level, researchers can use such as differential thermal analysis of solidification processes which is based on chemical analysis, but there are some proble ms. On the one hand, it cannot simulate the important role of asphalt in the hardening system, on the other hand, the applications of these equipments are numerous, and not specifically developed for road asphalt, which is expensive, the cost of evaluation of the hardening process in epoxy asphalt is too high. It isn't an ordinary scientific research institutes can undertake, and therefore, in this paper, researchers provide a methodology based on the asphalt test, simple quick and inexpensive detection and control of the intensity of the hardening process of epoxy asphalt changes.

\section{EPOXY RESINS AND HARDENING MECHANISM OF THIS TEST}

Epoxy resin is an epoxy group oligomer, which contains aliphatic, alicyclic or aromatic organic compounds as the backbone.

Epoxy resin usually is viscous liquids or solids at a room temperature, in the corresponding temperature can have hardening reaction to form three-dimensional structure of space-mesh polymer when it is mixed with the hardening agent. Hardened product has many characteristics, such as bond strength, small shrinkage, heat resistance, chemical resistance, good mechanical properties and excellent electrical performance.

However, in the course of the epoxy resin, their brittleness, poor weather and low ductility weaknesses also greatly limits the use of epoxy resin. To improve the brittleness of epoxy resin hardened product and ductility under normal circumstances, it mainly through the selection or synthes is of the appropriate hardening agent to change the molecular structure of hardened product to a certain extent, which can improve service performance.

According to structural characteristics, epoxy resin can be classified of glycidyl ether, glycidyl ester, glycidyl amines, alicyclic type epoxy resin, and epoxied olefin. Among them bisphenol epoxy resin type $A$ of the diglycidyl ether type is widely used in the family of the epoxy resin products. Two phenyl propane (bisphenol A) and epichlorohydrin with an alkaline catalyst condensate into the bisphenol epoxy resin type A which is currently used. The general formula of the condensation product (linear epoxy resin) which has an epoxy-based end-group is shown in Fig. 1:<smiles>CC(C)(CC(O)COc1ccc(C(C)(C)c2ccc(OC(C)(C)c3ccc(OCC4CO4)cc3)cc2)cc1)Oc1ccc(C(C)(C)c2ccc(OCC3CO3)cc2)cc1</smiles>

Figure 1. Exam Bisphenol epoxy resin type A 
Bisphenol epoxy resin type A molecular structure contains of epoxy which has strong response capability. On the main chain, there are many ethers, it is a linear polyether structure. A certain distance apart on the molecular chain there are many hydroxyls, it is a longchain polyols. There are still a lot of phenyls submethyls and isopropyls on the main chain. These features can play the following roles:

Epoxies and hydroxyls make resins reactive, with a strong cohesion and bonding strength in the condensation. Ether and hydroxyl is the polarity genes, which help to improve infiltration and adhesion force, ether bond and $\mathrm{C}-\mathrm{C}$ bond to make molecules with a certain submissive nature. Phenyls make hardened condensation heat resist and rigid. Experiments proof bisphenol epoxy resin type A is non-carcinogenic, teratogenic, non-cause mutation of cells, and can therefore be safe to use. Label E-55 and above of bisphenol epoxy resin type A are liquid at room temperature, they have a good construction performance, the price of E-55 is lower than the above labels. Based on the above advantages, researchers use E-55 for the modified as phalt. Tab.1, 2 list the primary and secondary characters of E-55, which are used in this experiment.

TABLE I. PRIMARY CHARACTERS OF BISPHENOL EPOXY RESIN TYPE A

\begin{tabular}{|c|c|c|c|}
\hline Component & $\begin{array}{c}\text { Viscosity } \\
\left(23^{\circ} \mathrm{C}\right) \\
/(\mathrm{Pa} \cdot \mathrm{s})\end{array}$ & $\begin{array}{c}\text { Epoxy } \\
\text { Equivalent } \\
\text { weight/(g/eq) }\end{array}$ & $\begin{array}{c}\text { Organic } \\
\text { modification } \\
\text { or solvent }\end{array}$ \\
\hline olefin epoxy & Semisolid & $241 \sim 292$ & $\begin{array}{c}\text { Active } \\
\text { agent or } \\
\text { organic } \\
\text { solvent }\end{array}$ \\
\hline
\end{tabular}

TABLE II. SECONDARY CHARACTERS OF BISPHENOL EPOXY RESIN TYPE A

\begin{tabular}{|c|c|c|}
\hline $\begin{array}{c}\text { Density }\left(23^{\circ} \mathrm{C}\right) \\
/\left(\mathrm{g} / \mathrm{cm}^{3}\right)\end{array}$ & Additive & Characteristic \\
\hline$\leqslant 1.10$ & no & combustible \\
\hline
\end{tabular}

The epoxy asphalt research and development is still in its initial stage, although the species vary greatly, the performance of them doesn't satisfy the market need well. At present the United States, Japan and China have made out the initiative developed epoxy asphalt, and according to their adoption of the matrix asphalt, resin, hardening agent, catalysts, processing technology, etc. the different hardening mechanisms are also different. However, these products of epoxy asphalt are still in the patent protection period, and the details of hardening system are unknown, in order to facilitate experiment, researchers set maleic as an example to simply introduce the conduct of the general mechanism of epoxy resin hardening process.

At first, with the catalyzation of Lewis base (tertiary amine compounds), male ic anhydride-based as phalt and other anhydride hardening agent act and the anhydride anion key is opened to carboxylic acid anions, and then carboxylic acid anions open the epoxy group to form oxygen anions; oxygen anions continue react with the epoxy and ultimately the product of mutual superposition, entanglement due to the two kinds of response is almost simultaneous, and formed a threedimensional interpenetrating polymer network. Not only formed a three-dimensional interpenetrating network structure, and eventually the main chain of the molecular of the condensate contain a lot of phenyls, which can provide greater strength. Researchers can change the extent degree of maleic anhydride to control the cross linking, furthermore to form both strength and fle xibility to meet the requirements of the epoxy asphalt.

\section{PEnEtRAtionseVAluAtion to ThE HARDENING TIME}

Since currently there is a big problem of Epoxy Asphalt that the control of operational time, it is called gel time or the period of application in che mical industry. Different hardening agent has different hardening rate. In order to find a suitable hardening agent of deck pavement asphalt. Researchers must first find a kind of hardener which has a long enough period of application, the mixture of it will not harden agglomeration mixture in a short period of time. Therefore, the change of the viscosity in the process of mixing and transport becomes particularly important.

Prior to this experiment, researchers have been through the most intuitive testing approach usually Brookfield viscometer to evaluate the changes of the viscosity in the hardening process, but the hardening system solidifies in the sample barrel and cannot be carried out to continue the measurement.

Researchers had tried $5^{\circ} \mathrm{C}, 10^{\circ} \mathrm{C}$ extension of degree study, but there are a great number of errors, the basic law cannot be observed.

We also used DSR (dynamic shear Rheometer), but the sample of DSR is required a solid sample before put in the device, and the epoxy solidified asphalt is basically high temperature resistant, and simply cannot test how its viscosity or modulus changes. Therefore, researchers finally decided to use penetration to measure the optimum hardening time.

For the test convenience and exclusion of other factors, this test considers binder viscosity changes only, removed aggregates wrapping. It is to inspect the viscosity changes when components $\mathrm{B}$ and $\mathrm{A}$ are mixing. Taking into account of the viscosity and penetration have a good correlation to test the, researchers eventually adopt the method of penetration to grasp and control the gelation speed purposes.

The final three kinds of epoxy asphalt penetration test data are shown in Tab. 3. Researchers made Fig. 3 according to Tab. 6 , and can see more obvious about the penetration changes of the three kinds of asphalt. 
T ABLE III. TWO TYPES AB-COMPONENT EPOXY ASPHALT MIXING PENETRATION AFTER THE CHANGE (HEAT TEMPERATURE OF $120{ }^{\circ} \mathrm{C}$ )

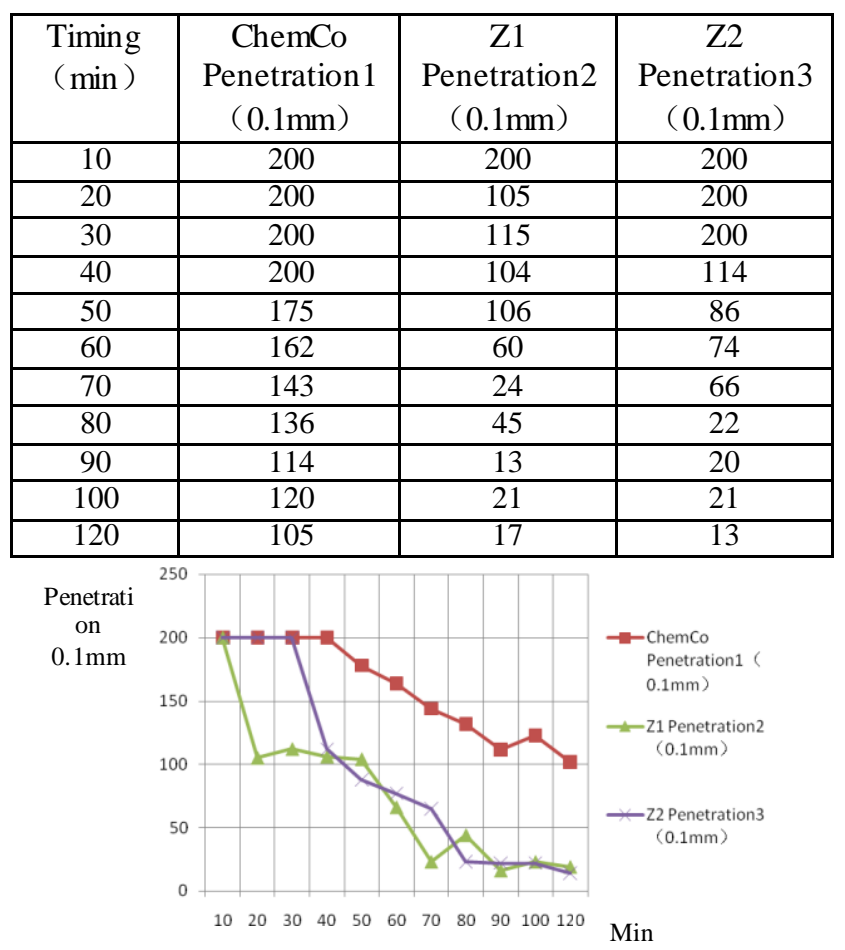

Figure 2. The changing of three penetrations

The penetrations $200(0.1 \mathrm{~mm})$ in figure are assumptive in order to facilitate drawing, not truly 200 . The after $20 \mathrm{~min}$ penetrations of the three lines are basically effective.

Basically can be seen from the figure, ChemCo asphalt changes as a linear in 120min, Z1 and Z2 generated a mutation, at $50 \mathrm{~min}$ and $30 \mathrm{~min}$ respectively. $\mathrm{Z} 1$ penetration goes into a acceleration drop stage at the $50 \mathrm{~min}, \mathrm{Z} 2$ has not been an accelerated decline phase, but has declined at a high rate and basically dropped below $70(0.1 \mathrm{~mm})$ in $40 \mathrm{~min}$. According to the experience of construction, and assuming that mixing, transportation, waiting, paving and compaction process takes two hours minimum, ChemCo asphalt which gels in 2 hours can meet the requirements, $\mathrm{Z} 1$, within 1 hour, can basically meet, while the $\mathrm{Z} 2$ cannot meet.

\section{CONCLUSIONS}

Due to the high viscosity of epoxy asphalt, its hardening process can not be inspected in conventional Brookfield viscometer. Researchers advocates penetration evaluation as indicators in its hardening process. According to the data shows in tests, the gel time of ChemCo and $\mathrm{Z} 1$ are long enough to meet construction demands, while Z2 isn't. By controlling the viscosity of the curing process, researchers have proved that N1 foamed epoxy asphalt has the longest construction operable time, which is up to $140 \mathrm{~min}$. Besides, Z1, Z2 and Che mCo epo xy as phalt have similar construction operable time between $70-90 \mathrm{~min}$.

\section{ACKNOWLEDGMENT}

This research was supported by the 1) 2014 Science and Technology Program of Ministry of Housing and Urban-Rural Development of the People's Republic of China, No. 2014-K1-025; 2) 2014 Technology Program of Shanghai Municipal Engineering Design Institute (Group) Co., Ltd. No. K2014K028.

\section{REFERENCES}

[1] Li Xiujun, Yuan Jianan, Dai Jingliang. Relationship between penetration of asphalt and rheological property[J].Journal of Chang'an University (Natural Science Edition). Mar. 2003 Vol.123 No.12

[2] Tan Jiqing, Xu Wei, Zhang Xiaoning. Finite element simulation and optimal analysis of surfacing on steel orthotropic bridge deck[J]. Journal of Southeast University (English Edition). Dec.2006 Vol.22 No.4

[3] Huang Wei, Liu Zhenqing. Research on theory and method of long2span steel bridges deck surfacing design[J]. China civil engineering journal. Jan.2005 Vol.38 No.11

[4] Xu Qing. Construction Techniques of Bridge Carriageway Pavement in Epoxy Asphalt[J]. Municipal Engineering Technology. Sep. 2006 Vol.24 No.5

[5] JT J-052-2000. Highway engineering asphalt and mixture test regulations [S]

[6] Huang Ming, Huang Wei-dong.Study on Impaction of Paving Wait ing Time on Performance of Epoxy Asphalt Mix[J].Journal of Building Materials.2012.2(1).Vol.15:122-125

[7] Li Guilin. Epoxy resin and dope[M].Chemistry Engineering Express. 2002

[8] Zhang Chunling ,Sun Guoen ,Zhang Li ,Na Hui. Curing properties of the novel curing agent of epoxy resin[J]. Journal of Jilin University (Engineering and Technology Edition). Mar. 2007 Vol. 37 No. 2

[9] Zhu Yiming. Research on the Performance of Domestic Epoxy Asphalt Mixture[D]. A Dissertation submitted to Southeast University for the Academic Degree of Master of Engineering. Feb.2006

[10] Huang Ming, Huang Weidong. Several Relative Problems of Epoxy Asphalt Solidifiers[J].Journal of Chongqing Jiaotong University(Natural Science) Oct.2009 Vol.28 No.25

[11] Peiyi Len. Airport Pavement Design.China Communication Press. 1995 : p.45-46. 